\title{
Aerolaserskaneerimise kasutamine metsakorralduse alusena
}

\author{
Tauri Arumäe $e^{1,2^{*}}$ ja Mait Lang ${ }^{1,3}$
}

Arumäe, T., Lang, M. 2020. Airborne laser scanning as a basis for forest mensuration. Forestry Studies | Metsanduslikud Uurimused 73, 136-144, ISSN 1406-9954. Journal homepage: http://mi.emu.ee/forestry.studies

\begin{abstract}
In this summary, we give an overview of the application of airborne laser scanning (ALS) data for predicting the main forest inventory variables in Estonia. When Estonia being one of the few countries with wall-to-wall ALS availability, the need for applicable models for Estonian forests was imminent. Over the past decade, different studies have been carried out to develop models for standing wood volume, forest height, canopy cover, canopy base height, and methods for monitoring height growth and detect small-scale harvests. The main findings showed strong correlations for all the studied parameters and different methods utilizing low-density lidar data for practical forest inventory purposes. Options for using repeated ALS measurements for continuous forest inventory are discussed.
\end{abstract}

Key words: airborne lidar, forest structure, practical forestry, sparse ALS point clouds.

Authors' addresses: ${ }^{1}$ Institute of Forestry and Rural Engineering, Estonian University of Life Sciences, Kreutzwaldi 5, 51014 Tartu, Estonia; ${ }^{2}$ State Forest Management Centre, Sagadi Village, EE-45403 Haljala, Estonia; ${ }^{1}$ Tartu Observatory, University of Tartu, 61602 Tõravere, Tartumaa, Estonia; *e-mail tauri.arumae@rmk.ee

\section{Sissejuhatus}

Metsamajanduslike otsuste langetamiseks on metsaomanikel vaja informatsiooni metsa kohta. Peamised takseertunnused, mille põhjal neid otsuseid langetatakse, on kasvava metsa tagavara, puistu kõrgus, rinnaspindala, koosseis, puistuelemendi keskmise puu diameeter ja vanus (Krigul, 1972). Lisaks eelnimetatud tunnustele on veel vaja infot metsa kasvukohatingimuste (boniteet), looduslike väärtuste (Laarmann et al., 2009) jms kohta. Tavapäraselt on neid tunnuseid hinnanud koolitatud taksaatorid välitööde käigus. Näiteks takseeriti metsaressursi arvestuse registri järgi 2019. aastal 164536 puistut kogupindalaga 205 853 hektarit ehk veidi alla 9\% Eesti metsamaast. Kliimamuutustest tingituna üha sagenevate häiringute ja kasvutingimuste muutuste kontekstis on aga 10-aastane tsükkel liiga pikk.

Koos tehnika arenguga on võetud kindel suund metsade kohta informatsiooni kogumiseks, kasutades kaugseiret lennukitelt ja satelliitidelt (Jakubauskas \& Price, 1997; Lang et al., 2012; 2014; 2018; Kuusk et al., 2019). Aerofotod on olnud Eestis metsakorralduse alusmaterjaliks juba alates 1960. aastate algusest, aga visuaalset tõlgendamist asendab järjest enam masintöötlusel põhinev analüüs. Üks kiiremini arenevaid

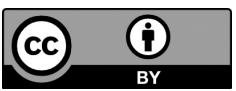

(C) 2020 by the authors. Licensee Estonian University of Life Sciences, Tartu, Estonia. This article is an open access article distributed under the terms and conditions of the Creative Commons Attribution (CC BY) license (http:/ / creativecommons.org/licenses/ by $/ 4.0 /)$. 
ja metsade takseerimises rakenduslikult kõige enam kasutust leidnud kaugseire meetod on aerolaserskaneerimine (ALS; Large \& Heritage, 2009). Kolmemõõtmeliste ALS punktipilvede abil saame kirjeldada väga detailselt kogu metsa vertikaalset struktuuri ning piisava punktitiheduse juures on võimalik saada infot kuni oksatasemeni välja (Næsset, 1997; Morsdorf et al., 2006; Arumäe, 2020). Metsa korraldamise juhendis (Metsakorralduse, 2018) aga mainitakse ainult aero- või ortofotode kasutamist eraldiste piiride täpsustamiseks.

Eestis on tehtud ALS-mõõtmisi riikli$\mathrm{ku}$ programmi raames juba aastast 2008 ja Maa-ameti eesmärk on olnud katta kogu riik nelja-aastaste tsüklitega (Maa-amet, 2018). Andmeid kogutakse kahel korral aastas - kevadel, kui puud pole veel lehes, ning suvel, kui mets on täies lehes. Mõõdistatavad alad kevadel ja suvel ei kattu. See tagab optimaalsed tingimused kevadiseks maapinna kaardistamiseks ja hiljem metsaressursi hindamiseks. Need andmed on kõigile vabalt alla laaditavad ning on publitseeritud mudelite põhjal sobilikud Eesti metsades peamiste takseertunnuste hindamiseks (Arumäe, 2020). Alljärgnevalt võtame lühidalt kokku mõned Eestis ja mujal tehtud uuringud, mis käsitlevad puistute kõrguse, tüvemahu ja struktuuri variatsiooni hindamist.

\section{ALS-i põhine takseertunnuste hindamine}

Peamised tunnused, mida ALS-i põhjal hinnatakse, on metsa kõrgus $H$ ja kasvava metsa tagavara $V$. Aerolidari mõõtmistele tugineva metsa kõrguse $\left(H_{\text {ALS }}\right)$ hindamiseks on välja töötatud protsentiilide meetod, kus punktipilvede kohta arvutatakse punktide kõrguste (h) jaotust kirjeldavad meetrikud, mida hiljem saab (lineaarsete) mudelite kaudu seostada metsas mõõdetud kõrgusega. Punktipilvede vertikaalse jaotuse ülemised protsentiilid $\left(H_{\mathrm{Px}}\right)$ on väga tugevas korrelatsioonis mõõdetud kõrgusega
$\left(R^{2}>0,9\right)$ ja uurimustulemuste põhjal (Lang et al., 2012; Arumäe \& Lang, 2016; Lang et al., 2017) saab väita, et kõrguse prognoosimine aerolidari andmetelt on ligilähedase või isegi parema täpsusega, mis saadakse tavalise metsatakseerimise käigus.

Mudelite parameetrite lähendamiseks on empiiriliste andmetena kasutatavad peamiselt statistilise metsainventuuri (SMI) proovitükid (Adermann, 2010), kasvukäigu proovitükid (Kiviste et al., 2015) või ka näiteks Metsaregistris (Metsaregister, 2020) olevad eraldiste takseerandmed. Lisaks on rajatud katsealadele uusi ringproovitükke, millel meile huvi pakkuvaid tunnuseid maapeal mõõdetakse (Lang et al., 2012; Arumäe \& Lang, 2016). Peamine eelis SMI proovitükkide kasutamisel on kogu regionaalse eripärasuse kirjeldamine, mis lubab mudeleid lähendada näiteks eri regioonidele (Kotivuori et al., 2018), mis on väga oluline just metsa tagavara hindamisel, nagu näitavad ka Eestis tehtud uurimused (Arumäe, 2020). Peale mudelite parameetrite hindamist ja mudelite valideerimist on meil võimalik konstrueerida kogu Eestit katvad metsa kõrguse ja kasvava metsa tagavara kaardid (joonis 1).

Kasvava metsa tagavara hindamiseks ALS-i andmete põhjal $\left(V_{\text {ALS }}\right)$ kasutatakse mudelites koos peamiselt kahte tüüpi tunnuseid - kõrgusprotsentiile $\left(H_{p x}\right)$ ja puistu tihedust kirjeldavaid meetrikuid. Üks puistu tihedust kirjeldav tunnus on võrade suhteline pikkus (Arumäe \& Lang, 2013), aga otsene puistu tiheduse indikaator on ALS-i põhine võrastiku katvus $\left(C_{\mathrm{ALS}}\right)$, mis arvutatakse peegelduste $\left(N_{\mathrm{ALS}}\right)$ suhtearvuna lähtudes kõrgusnivoost $(z)$ :

$$
C C_{\mathrm{ALS}}=\frac{100 \cdot N_{A L S}(h>z)}{N_{A L S}} .
$$

Need kaks tunnust $H_{P x}$ ja $C C_{\text {ALS }}$ kirjeldavad ära suure osa puistu tüvemahu variatsioonist. Kuigi punktipilvede meetrikuid on palju, näitavad katsed, et nende kõikide kasutamine mudelites lisaks paarile põhitunnusele ei anna tüvemahu prognoosimisel 

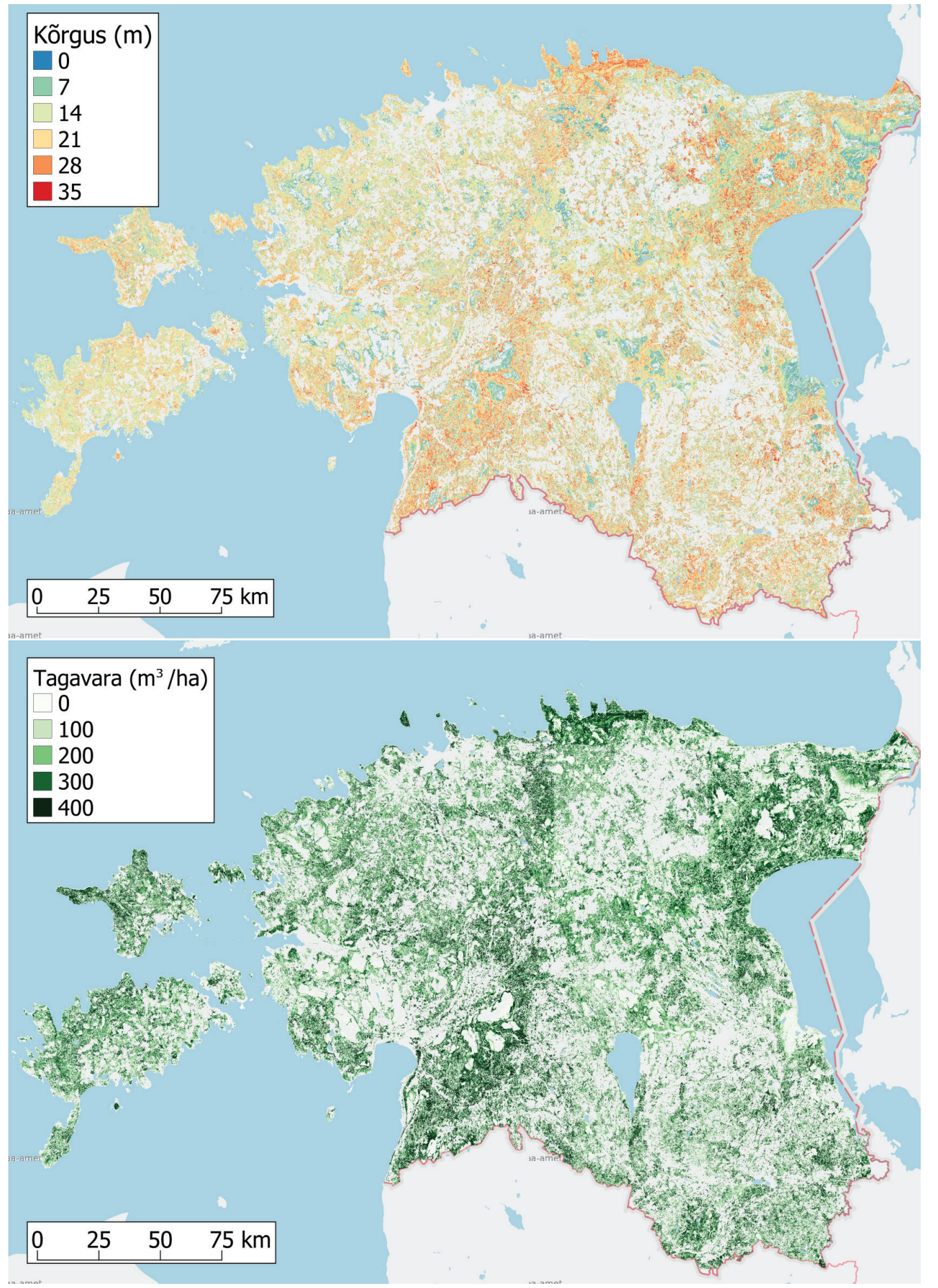

Joonis 1. ALS-põhine Eesti metsade kõrguskaart (ülemine) ja kasvava metsa tagavara kaart (alumine) koostatud Maa-ameti 2016-2019 lennuandmete põhjal.

Figure 1. Forest height (upper) and standing wood volume (lower) map based on the Estonian Land Board ALS data from 2016-2019. 
statistiliselt olulist täpsuse kasvu. Mudelite koostamiseks saab lisaks regressioonimeetodile kasutada masinõppealgoritme nagu k-lähima naabri meetod $(k-\mathrm{NN}$, McRoberts \& Tomppo, 2007), Random Forest või närvivõrgud (Ayrey \& Hayes, 2018). Siiski saab Cosenza et al. (2020) uurimuse põhjal väita, et nende meetodite vahel tulemuse täpsus suurel määral ei erine. Eestis välja töötatud $V_{\mathrm{ALS}}$ mudelid (Arumäe ja Lang, 2016) kasutavad sarnaselt kõrgusprotsentiile ja punktitiheduse jaotuse hinnanguid, ning prognoositud tüvemaht on sarnase suhtelise veahinnanguga nagu Soomes ja Norras (Arumäe \& Lang, 2016; Kotivuori et al., 2016; Noordermeer et al., 2019a).

Laserimpulsi peegelduste asukohti mõjutab mõningal määral ka puistu liigiline koosseis. Lehemassi jaotus ja hulk võrastikus ning ka võrade kujud erinevad puuliigiti ning see tingib mõningased süstemaatilised erinevused ka ALS punktipilvede meetrikutele tuginevate prognoosmudelite parameetrite väärtustes. Seega on lisaks aerolidari andmete regionaalsetele eripäradele oluline eristada mudelites puuliigid, mille tarbeks on Eestis välja töötatud puistute liigilise koosseisu kaart (Lang et al., 2018). Selle kaardi rakendamisel on potentsiaali peale suviste andmete kasutada ka kevadisi ALS-i andmeid, kus leht- ja okaspuuliikide vahelised erinevused peegelduste kõrgusjaotuses on statistiliselt oluliselt erinevad (Arumäe \& Lang, 2018).

\section{Masinõpe ja ALS-i andmed}

Kuigi Cosenza et al. (2020) näitasid puistu tagavara põhjal, et masinõppe ja lihtsate lineaarmudelite prognooside vahel olulist erinevust ei esine, siis masinõppe võimekust suuri andmehulkasid käidelda ja neist kasulikku infot esile tuua ei saa alahinnata. Näiteks on ka Eestis välja töötatud puistu liigilise koosseisu kaardi koostamiseks kasutatud algoritmi Random Forest (Lang et al., 2018). Samas eeldab masinõppealgoritmide kasutamine prognoosmudelite koos- tamiseks palju suuremat hulka näidiseid (vaatlusi), kui on vaja regressioonimudelite jaoks. Seega kui empiirilises andmestikus on kirjeldavate tunnuste ja prognoositava tunnuse vahel põhjuslikud ja tugevad seosed, mida saab lähendada mõne funktsiooniga, siis regressioonimudeli koostamine on masinõppemudelist otstarbekam.

Tulevikku silmas pidades võiks potentsiaalseid masinõppealgoritmidele põhinevaid rakendusi tekkida bioloogilise mitmekesisuse ja puistute looduslikkuse prognoosimisel. Erinevate uuringute põhjal on teada, et metsade struktuur, mida ALS-i andmetelt on võimalik kirjeldada, on kaudsel viisil seostatav just looduslikkuse tunnustega (Nagendra, 2001; Müller \& Vierling, 2014). Elurikkuse kui kompleksmuutuja hindamiseks sobiva rakenduse väljatöötamiseks oleks samuti väga oluline elurikkust kirjeldavaid tunnuseid kvantitatiivselt hinnata ja otsida võimalusi ALS-i andmetest mõõdetavate metsatunnuste kasutamiseks (Põldveer et al., 2020).

Lisaks laialdasemale andmete kättesaadavusele on laserskaneerimise tehnoloogias toimumas areng väiksemate ja kergemate skannerite suunas, mis lubab neid kasutada maapealseteks täppismõõtmisteks (terrestrial laser scanning - TLS) või ka droonidelt mõõdistamiseks. Ülitihedad punktipilved $\left(>50 \mathrm{~m}^{-2}\right)$ avavad palju uusi erinevaid võimalusi rakendusteks - näiteks kõrguskasvu modelleerimine ja seiramine (Lang et al., 2017), üksikpuude tuvastamine (Balsi et al., 2018), võrakujudele tuginev puuliikide eristamine (Korpela et al., 2010) või ka otsene puutüve rinnasdiameetri hindamine (Xu et al., 2019). Tihedate andmestike kasutamine praktilises metsakorralduses on praegusel ajal siiski võimalik ainult lokaalsete uuringute jaoks eelkõige mõõtmiste suhteliselt kõrge pinnaühiku hinna tõttu.

\section{ALS-i andmete aegread}

ALS-i andmete aegread leiavad järjest enam kasutamist, kuna üha enam riike on 
alustanud süsteemset riiklikku laserskaneerimist. Maa-ameti tehtud lidarmõõtmiste andmebaasis on kogu Eesti kohta juba vähemalt kahekordne andmekiht, mis annab võimaluse lisaks eespool mainitud tunnuste hetkeväärtustele tuvastada ja hinnata erinevate tunnuste muutuseid (joonis 2). Peamised huvipakkuvad muutused on metsade juurdekasv ja kõrguse kasv (Arumäe et al., 2020). Aegridade olemasolu annab võimalusi puistute boniteerimiseks sobilike mudelite loomisel (Noordermeer et al., 2020; Guerra-Hernández et al., 2021), ning samuti harvendusraiete ja nendega sarnanevate häiringute tuvastamiseks, kui muutub puistu domineeriva rinde võrastiku tihedus või kõrgus (Lang \& Arumäe, 2018; Noordermeer et al., 2019b; Arumäe et al., 2020).
Aegridade kasutamisel tuleb arvestada, et laserimpulsi peegeldumise tekkimine metsast on teatud juhuslikkust sisaldav protsess, mida mõjutavad muu hulgas nii taimkatte struktuur, skaneerimisnurk kui ka skanneri seadistus ja mõõtmiskõrgus. Korduvmõõtmistel avaldab see juhuslikkus mõju hõreda skaneeringu puhul, mis teisalt võimaldab ühe ruutkilomeetri hinda hoida majanduslikult sobivana rutiinsete ja suurel alal tehtavate mõõtmistööde jaoks. Hõredaks skaneeringuks nimetame siinkohal punktitihedust alla 5 ruutmeetri kohta. Maa-ameti eelarve võimaldab praegu saavutada 0,5-2,0 punkti ruutmeetri kohta. Laserskaneerimise aegridade (joonis 2, 3) analüüsimisel tuleb arvestada ka fenoloogia mõjuga. Lageraiesarnased häiringud muudavad puistu struktuuri nii palju, et

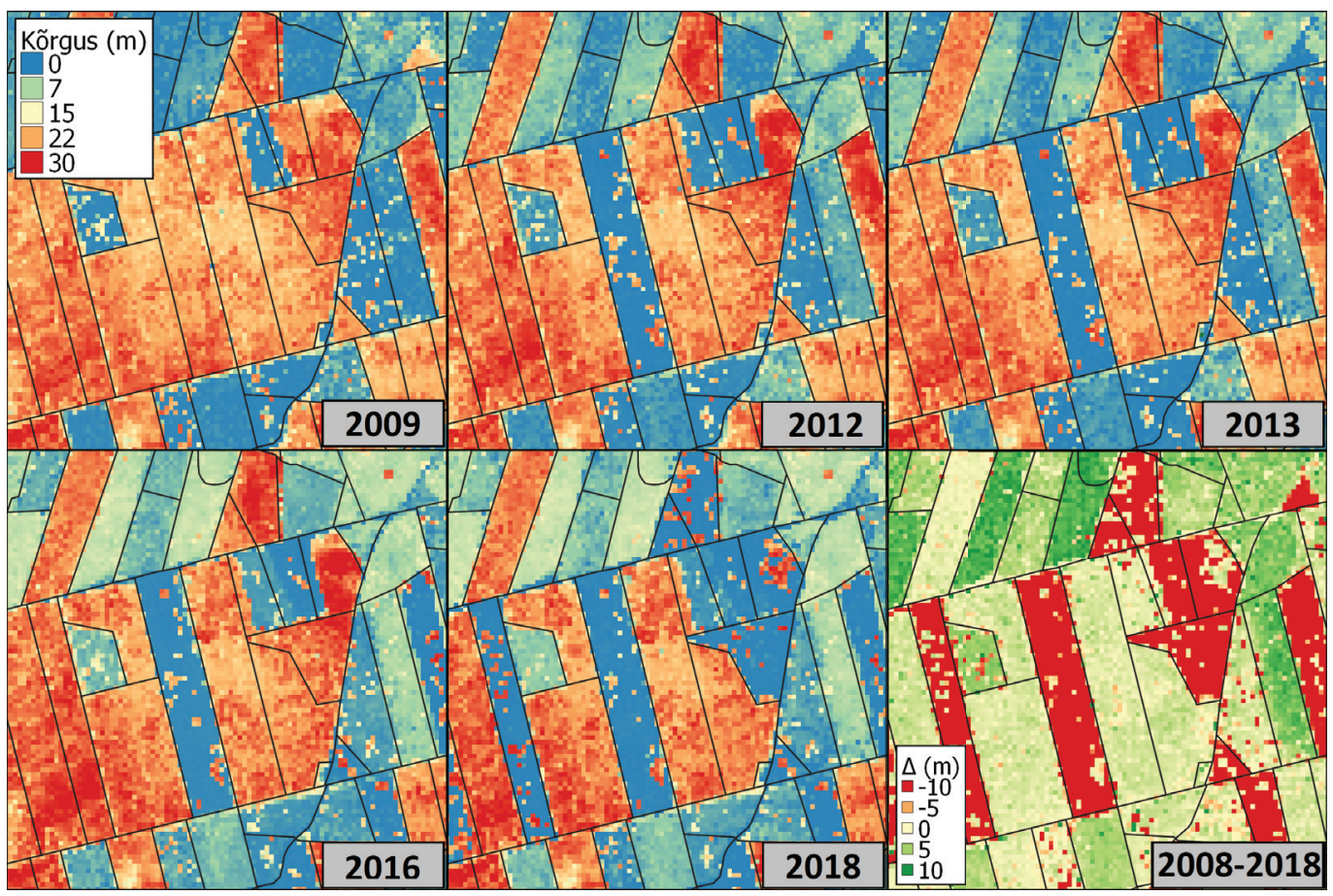

Joonis 2. ALS-i andmete aegrida aastast 2009 kuni 2018, millel kujutatud 10-meetrise piksliga metsa kõrgushinnangu muutus. Viimasel, muutuste kaardil vastavad tumepunased toonid suurele kõrguse kahanemisele (nt lageraie) ja tumedad rohelised toonid näitavad kõrguskasvu noorendikes.

Figure 2. ALS data timeseries map from 2009 to 2018, including the forest height change on a 10 metre pixel. The bottom-right map shows a drastic decrease in height (clearcuts) in red and rapid growth with dark green (young stands). 

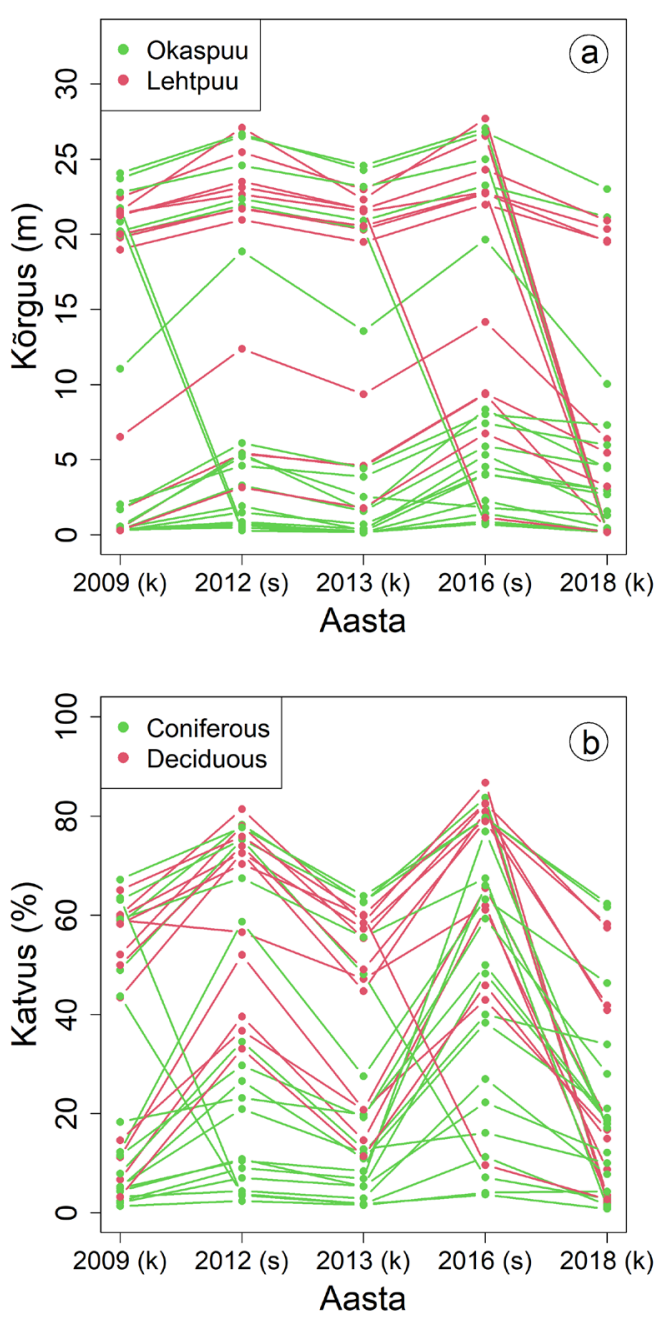

Joonis 3. Punktipilve kirjeldavate meetrikute aegridade näited: a) kõrgusjaotuse 90-protsentiil, b) katvus. Suur kõrguse kahanemine viitab lageraiele. Mõõtmised on tehtud kevadel ( $k$ ) või suvel (s). Lehepinnaindeksi erinevuste ja skannerite omaduste mõju tõttu ei ole aegread siledad.

Figure 3. Examples of a) 90th height percentile and b) canopy cover change over the course of 9 years. Labels indicate spring ( $k$ ) and summer (s) conditions. Large drops in values refer to clearcuts and the variation is related to differences in fenological state and scanner settings. on tuvastatavad olenemata lehestiku arengust. Puistu kõrguse kasvu või võrastiku (tervisliku) seisundi hindamisel tuleb aga kindlasti arvestada ka ALS-mõõtmiste aastaajaga (joonis 3).

Metsakorralduse alusena on lidarmõõtmiste andmed sama väärtuslikud kui aero- ja ortofotod. Kuigi ka punktipilved on raalkeskkonnas visualiseeritavad, siis nende peamine väärtus seisneb võimaluses hinnata puistute kõrgust ning prognoosida tüvemahtu mudelite abil. Samas on joonise (3) järgi ilmne, et vale aastaaja mudelite kasutamisel saadakse süstemaatilised vead prognoositud kõrguses ja tüvemahus. Arvestades ka seda, et regiooniti ja erineva aastate lendude puhul ilmnevad Eestis punktipilvede meetrikute ja prognoositavate takseertunnuste seostes erinevused, tuleb tõdeda, et üldise mudeli kehtestamine ALS-i andmete töötlemiseks ei ole reaalne ja iga ALS-i mõõtmistulemuste komplekti jaoks on vaja lähendada uuesti mudelite parameetrite väärtused.

\section{Kokkuvõte}

- Maa-ameti tehtavate lidarmõõtmiste andmed on Eestis kasutatavad puistute kõrguse ja tüvemahu hindamiseks metsakorralduse alusmaterjalina.

- Kõrguse ja tüvemahu prognoosimiseks sobivad hästi ka tavalised regressioonimudelid.

- Hõredad ALS-mõõdistuse punktipilvede aegread sobivad muutuste tuvastamiseks, kuid arvestada tuleb fenoloogia ja mõõtmistehniliste karakteristikute mõjudega.

- Vajadus iga ALS-i mõõtmisseeria jaoks mudelite parameetrid lähendada seab veidi ebavõrdsesse olukorda väiksemad metsakorraldusettevõtted, kellel pole vahendeid piisava hulga proovitükkide rajamiseks.

- Kaugseire meetodid ei asenda välimõõtmisi, pigem optimeerivad välitöid ja lubavad kallinevat tööjõudu nutikamalt rakendada. 


\section{Kasutatud kirjandus}

Adermann, V. 2010. Development of Estonian National Forest Inventory. - Tomppo, E., Gschwantner, T., Lawrence, M., McRoberts, R.E. (eds.). National Forest Inventories: Pathways for Common Reporting. Heidelberg, Springer, 171-184.

Arumäe, T. 2020. Estimating forest variables using airborne lidar measurements in hemi-boreal forests. - Doctoral thesis. Tartu, Estonian University of Life Sciences. 195 pp. http:// dspace.emu.ee/xmlui/handle/10492/5764.

Arumäe, T., Lang, M. 2013. A simple model to estimate forest canopy base height from airborne lidar data. - Forestry Studies / Metsanduslikud Uurimused, 58, 46-56. (In Estonian with English summary).

Arumäe, T., Lang, M. 2016. ALS-based wood volume models of forest stands and comparison with forest inventory data. - Forestry Studies / Metsanduslikud Uurimused, 64, 5-16. https:/ / doi.org/10.1515/fsmu-2016-0001. (In Estonian with English summary).

Arumäe, T., Lang, M. 2018. Estimation of canopy cover in dense mixed-species forests using airborne lidar data. - European Journal of Remote Sensing, 51(1), 132-141. https:/ / doi.or g/10.1080/22797254.2017.1411169.

Arumäe, T., Lang, M., Laarmann, D. 2020. Thinning- and tree-growth-caused changes in canopy cover and stand height and their estimation using low-density bitemporal airborne lidar measurements - a case study in hemi-boreal forests. - European Journal of Remote Sensing, 53(1), 113-123. https:/ / doi.or $\mathrm{g} / 10.1080 / 22797254.2020 .1734969$.

Ayrey, E., Hayes, D.J. 2018. The use of threedimensional convolutional neural networks to interpret LiDAR for forest inventory. - Remote Sensing, 10, 649. https://doi.org/10.3390/ rs10040649.

Balsi, M., Esposito, S., Fallavollita, P., Nardinocchi, C. 2018. Single-tree detection in high-density LiDAR data from UAV-based survey. - European Journal of Remote Sensing, 51, 679-692. https:/ / doi.org/10.1080/22797254.2018.1474722.

Cosenza, D.N., Korhonen, L., Maltamo, M., Packalen, P., Strunk, J.L., Næsset, E., Gobakken, T., Soares, P., Tomé, M. 2020. Comparison of linear regression, k-nearest neighbour and random forest methods in airborne laserscanning-based prediction of growing stock. Forestry, 2020, 1-13. https:/ / doi.org/10.1093/ forestry/cpaa034.

Guerra-Hernández, J., Arellano-Pérez, S., González-Ferreiro, E., Pascual, A., Altelarrea, V.S., Ruiz-González, A.D., Álvarez-González, J.G. 2021. Developing a site index model for P.Pinaster stands in NW Spain by combining bi-temporal ALS data and environmental data. - Forest Ecology and Management, 481, 118690. https:/ / doi.org/10.1016/j.foreco.2020.118690.
Jakubauskas, M., Price, K.P. 1997. Empirical relationships between structural and spectral factors of Yellowstone lodgepole pine forests. - Photogrammetric Engineering and Remote Sensing, 63, 1375-1381.

Kiviste, A., Hordo, M., Kangur, A., Kardakov, A., Laarmann, D., Lilleleht, A., Metslaid, S., Sims, A., Korjus, H. 2015. Monitoring and modeling of forest ecosystems: the Estonian Network of Forest Research Plots. - Forestry Studies / Metsanduslikud Uurimused, 62, 26-38. https://doi.org/10.1515/fsmu-2015-0003.

Korpela, I., Ørka, H.O., Maltamo, M., Tokola, T., Hyyppä, J. 2010. Tree species classification using airborne LiDAR - effects of stand and tree parameters, downsizing of training set, intensity normalization, and sensor type. Silva Fennica, 44(2), 319-339.

Kotivuori, E., Korhonen, L., Packalen, P. 2016. Nationwide airborne laser scanning based models for volume, biomass and dominant height in Finland. - Silva Fennica, 50, 1567. http:/ / dx.doi.org/10.14214/sf.1567.

Kotivuori, E., Maltamo, M., Korhonen, L., Packalen, P. 2018. Calibration of nationwide airborne laser scanning based stem volume models. - Remote Sensing of Environment, 210, 179-192.

Krigul, T. 1972. Forest Mensuration. (Metsatakseerimine). Tallinn, Valgus. 359 pp. (In Estonian)

Kuusk, A., Kuusk, J., Lang, M. 2019. A statistical forest reflectance model. - Remote Sensing, 11, 2749. https://doi.org/10.3390/rs11232749.

Laarmann, D., Korjus, H., Sims, A., Stanturf, J., Kiviste, A., Köster, K. 2009. Analysis of forest naturalness and tree mortality patterns in Estonia. - Forest Ecology and Management, 258, 187-195.

Lang, M., Arumäe, T. 2018. Assessment of forest thinning intensity using sparse point clouds from repeated airborne lidar measurements. - Forestry Studies / Metsanduslikud Uurimused, 68, 40-50. https://doi. org/10.2478/fsmu-2018-0004.

Lang, M., Arumäe, T., Anniste, J. 2012. Estimation of main forest inventory variables from spectral and airborne lidar data in Aegviidu test site, Estonia. - Forestry Studies / Metsanduslikud Uurimused, 56, 27-41. https:/ / doi.org/10.2478/v10132-012-0003-7. (In Estonian with English summary).

Lang, M., Arumäe, T., Lükk, T., Sims, A. 2014. Estimation of standing wood volume and species composition in managed nemoral multi-layer mixed forests by using nearest neighbour classifier, multispectral satellite images and airborne lidar data. - Forestry Studies / Metsanduslikud Uurimused, 61, 4768. https:/ / doi.org/10.2478/fsmu-2014-0010. 
Lang, M., Arumäe, T., Laarmann, D., Kiviste, A. 2017. Estimation of change in forest height growth. - Forestry Studies / Metsanduslikud Uurimused, 67, 5-16. https://doi. org/10.1515/fsmu-2017-0009. (In Estonian with English summary).

Lang, M., Kaha, M., Laarmann, D., Sims, A. 2018. Construction of tree species composition map of Estonia using multispectral satellite images, soil map and a random forest algorithm. ForestryStudies / Metsanduslikud Uurimused, 68, 5-24. https://doi.org/10.2478/fsmu-20180001.

Large, A.R.G., Heritage, G.L. 2009. Laser scanning - evolution of the discipline. - Heritage, G.L., Large, A.R.G. (eds.). Laser Scanning for the Environmental Sciences. Chichester, West Sussex, John Wiley \& Sons, 1-20. https:/ / doi. org/10.1002/9781444311952.ch1.

Maa-amet. 2018. Aerial laserscanning heightpoints. (Aerolaserskaneerimise kõrguspunktid). [WWW document]. - URL https://geoportaal. maa met.ee/est/Andmed-ja-kaardid / Topograafilised-andmed/Korgusandmed/ Aerolaserskaneerimise-korguspunktid-p499. html. [Accessed 16 November 2020]. (In Estonian).

McRoberts, R.E., Tomppo, E.O. 2007. Remote sensing support for national forest inventories. - RemoteSensing of Environment, 110, 412-419. https://doi.org/10.1016/j.rse.2006.09.034.

Metsakorralduse. 2018. Forest inventory act. (Metsa korraldamise juhend). - RT I, 31.08.2018, 8. (In Estonian).

Metsaregister. 2020. Forestregister. (Metsaregister). [WWW document]. - URL https://register. metsad.ee/. [Accessed 26 November 2020]. (In Estonian).

Morsdorf, F., Kötz, B., Meier, E., Itten, K.I., Allgöwer, B. 2006. Estimation of LAI and fractional cover from small footprint airborne laser scanning data based on gap fraction. Remote Sensing of Environment, 104, 50-61. https://doi.org/10.1016/j.rse.2006.04.019.
Müller, J., Vierling, K. 2014. Assessing biodiversity by airborne laser scanning. - Maltamo M., Næsset E., Vauhkonen J. (eds.). Forestry Applications of Airborne Laser Scanning. Managing Forest Ecosystems, vol 27. Dordrecht, Springer, 357-374. https://doi. org/10.1007/978-94-017-8663-8_18.

Nagendra, H. 2001. Using remote sensing to assess biodiversity. - International Journal of Remote Sensing, 22(12), 2377-2400.

Næsset, E. 1997. Determination of mean tree height of forest stands using airborne laser scanner data. - ISPRS Journal of Photogrammetry and Remote Sensing, 52, 49-56.

Noordermeer, L., Bollandsås, O.M., Ørka, H.O., Næsset, E., Gobakken, T. 2019a. Comparing the accuracies of forest attributes predicted from airborne laser scanning and digital aerial photogrammetry in operational forest inventories. - Remote Sensing of Environment, 226, 26-37. https://doi.org/10.1016/j. rse.2019.03.027.

Noordermeer, L., Økseter, R., Ørka, H.O., Gobakken, T., Næsset, E., Bollandsås, O.M. 2019b. Classification of forest change by using bitemporal airborne laser scanner data. - Remote Sensing, 11(18), 2145. https://doi. org/10.3390/rs11182145.

Noordermeer, L., Gobakken, T., Næsset, E. Bollandsås, O.M. 2020. Predicting and mapping site index in operational forest inventories using bitemporal airborne laser scanner data. Forest Ecology and Management, 457, 117768. https://doi.org/10.1016/j.foreco.2019.117768.

Põldveer, E., Korjus, H., Kiviste, A., Kangur, A., Paluots, T., Laarmann, D. 2020. Assessment of spatial stand structure of hemiboreal conifer dominated forests according to different levels of naturalness. - Ecological Indicators, 110, 105944. https://doi.org/10.1016/j. ecolind.2019.105944.

Xu, Q., Li, B., Maltamo, M., Tokola, T., Hou, Z. 2019. Predicting tree diameter using allometry described by non-parametric locally-estimated copulas from tree dimensions derived from airborne laser scanning. - Forest Ecology and Management, 434, 205-212. https://doi. org/10.1016/j.foreco.2018.12.020. 


\section{Airborne laser scanning as a basis for forest mensuration}

\section{Tauri Arumäe and Mait Lang}

\section{Summary}

In this short summary, we gave an overview of the application of airborne laser scanning (ALS) data for predicting the main forest inventory variables in Estonia (Lang et al., 2012; Arumäe \& Lang, 2016; Arumäe \& Lang, 2018; Arumäe, 2020). Estonia is one of the few countries with multitemporal wall-to-wall airborne lidar availability (Maa-amet, 2018), and the need for practical outputs is growing.

The most common parameters estimated from ALS data are standing wood volume (Arumäe \& Lang, 2016; Kotivuori et al., 2016; Kotivuori et al., 2018) and forest height (Næsset, 1997; Lang et al., 2012; Lang et al., 2017) (Figure 1). An indicator of forest density and light conditions is canopy base height, which can further be used for crown length assessment (Arumäe \& Lang,
2013). Another indicator variable for competition and stand density is ALS-based canopy cover (model 1) (Arumäe \& Lang, 2018; Arumäe, 2020), which is also the main variable in standing wood volume models. With multitemporal data available, different changes in forest structure can be monitored, like height growth (Figure 2) or small-scale harvests (Arumäe et al., 2020). Multitemporal data provides new options, but also raises the need to solve the variability in results, which is mostly related to differences between scanner and flight settings, and the influence of phenology (Figure 3). The main findings of Arumäe (2020) showed strong correlations for all the studied parameters and low-density lidar data is applicable for practical purposes and forest resource monitoring. 